\title{
PERLINDUNGAN KONSUMEN TERHADAP KECURANGAN PENGISIAN BAHAN BAKAR MINYAK PADA STASIUN PENGISIAN BAHAN BAKAR UMUM DI BALI $^{*}$
}

\author{
Oleh: \\ I Made Satria Wibawa** \\ Anak Agung Ketut Sukranatha** \\ I Made Dedy Priyanto**** \\ Bagian Hukum Bisnis Fakultas Hukum Universitas Udayana
}

\begin{abstract}
Abstrak
Bahan Bakar Minyak memiliki peranan yang penting dan merupakan salah satu kebutuhan yang tidak bisa dipisahkan dalam kegiatan masyarakat. Di Indonesia, peran BBM sangat penting dalam kehidupan masyarakat, terutama dalam kegiatan transportasi. Penggunaan transportasi di Indonesia tercatat cukup tinggi. Melihat tingginya jumlah kendaraan yang ada di Indonesia, tentu saja kebutuhan BBM juga kian meningkat. Hal tersebut dibuktikan dengan banyaknya Stasiun Pengisian Bahan Bakar Umum di hampir seluruh daerah baik di kota sampai ke pelosok desa. SPBU merupakan tempat dimana kendaraan memperoleh bahan bakar. Dalam pelaksanaan kegiatan jual beli BBM antara konsumen dan SPBU, masih adanya permasalahan yang dihadapi. Salah satu keluhan para konsumen yang sering terjadi adalah adanya kecurangan dalam pengisian bahan bakar di SPBU.

Metode penelitian yang digunakan dalam penulisan skripsi ini adalah metode penelitian yuridis empiris. Jenis pendekatan yang digunakan dalam penelitian ini yaitu pendekatan fakta dan pendekatan perundang-undangan yaitu pendekatan dengan menggunakan legislasi dan regulasi.

"Tulisan ini merupakan ringkasan skripsi

${ }^{* *}$ I Made Satria Wibawa adalah mahasiswa Fakultas Hukum Universitas Udayana, Korespodensi: satriawibawa081@gmail.com

${ }^{* * *}$ Dosen Fakultas Hukum Universitas Udayana

${ }^{* * * *}$ Dosen Fakultas Hukum Universitas Udayana
\end{abstract}


Hasil penelitian ini menunjukkan bahwa faktor-faktor yang menyebabkan terjadinya kecurangan saat pengisian BBM pada SPBU di Bali adalah dari oknum-oknum petugas operator SPBU itu sendiri yaitu dengan adanya kesempatan untuk melakukan kecurangan, sifat serakah, dan adanya tekanan kebutuhan yang mendesak. Pelaksanaan perlindungan hukum bagi konsumen BBM ada 2 yaitu perlindungan hukum Preventif atau berupa pencegahan, dan perlindungan hukum Represif yaitu perlindungan akhir berupa sanksi. Dalam upaya perlindungan hukum bagi konsumen BBM, Dinas Perindustrian dan Perdagangan Provinsi Bali dan Kabupaten/kota melakukan 2 sarana perlindungan hukum tersebut. Dalam bentuk perlindungan hukum yang Preventif, Disperindag melakukan kegiatan Tera Ulang terhadap alat ukur yang digunakan dalam kegiatan perdagangan, yang dalam hal ini yaitu mesin pompa bahan bakar pada SPBU di Bali. Selanjutnya dalam bentuk Represif, Disperindag bekerja sama dengan aparat hukum yaitu kepolisian, melakukan penyegelan terhadap SPBU-SPBU di Bali yang diduga melakukan kecurangan ataupun perbuatan yang melanggar aturan perundang-undangn yang telah ditetapkan.

\title{
Kata Kunci: Bahan Bakar Minyak, Stasiun Pengisian Bahan Bakar Umum, Kecurangan, Perlindungan Hukum.
}

\begin{abstract}
Fuel Oil has an important role and is one of the needs that cannot be separated in community activities. In Indonesia, the role of $B B M$ is very important in people's lives, especially in transportation activities. Transportation use in Indonesia is quite high. Seeing the high number of vehicles in Indonesia, of course the need for fuel is also increasing. This is evidenced by the number of Public Refueling Stations in almost all regions in the city to remote villages. Gas stations are places where vehicles get fuel. In the implementation of fuel buying and selling activities between consumers and gas stations, there are still problems faced. One of the complaints of consumers that often happens is the cheating in refueling at gas stations.

The research method used in writing this thesis is an empirical juridical research method. The type of approach used in this research is the approach to facts and the legislative approach, namely the approach using legislation and regulation.
\end{abstract}


The results of this study indicate that the factors that cause cheating when filling in fuel at gas stations in Bali are from the individual officers of the gas station operator itself, namely by the opportunity to commit fraud, greediness, and the pressure of urgent needs. There are 2 legal protections for consumers of BBM, namely Preventive legal protection or in the form of prevention, and repressive legal protection, namely final protection in the form of sanctions. In the effort of legal protection for consumers of BBM, the Industry and Trade Office of the Province of Bali and the Regency / city carry out these two legal protection facilities. In the form of Preventive legal protection, Disperindag conducts Tera Re activity on measuring instruments used in trading activities, which in this case are fuel pump engines at gas stations in Bali. Furthermore, in the form of a repressive, Disperindag cooperates with the legal apparatus, namely the police, sealing the gas stations in Bali that are suspected of cheating or acts that violate the laws and regulations that have been set.

\section{Keywords:Fuel Oil, Public Fueling Station, Fraud, Legal Protection.}

\section{PENDAHULUAN}

\section{$1.1 \quad$ Latar Belakang}

Di Indonesia, peran BBM sangat penting dalam kehidupan masyarakat, terutama dalam kegiatan transportasi. Untuk memenuhi semua kebutuhan konsumen akan BBM di Indonesia, pengadaan BBM ini harus dikelola dan diadakan oleh pemerintah sesuai dengan Undang-Undang Dasar Negara Republik Indonesia Tahun 1945 Pasal 33 ayat (2). Penggunaan transportasi di Indonesia tercatat cukup tinggi. Melihat tingginya jumlah kendaraan yang ada di Indonesia, tentu saja kebutuhan BBM juga kian meningkat. Hal tersebut dibuktikan dengan banyaknya Stasiun Pengisian Bahan Bakar Umum yang selanjutnya disebut SPBU di hampir seluruh daerah baik di kota sampai ke pelosok desa. SPBU merupakan tempat dimana kendaraan memperoleh 
bahan bakar. SPBU sendiri umumnya menyediakan beberapa jenis bahan bakar, seperti bensin, solar, E85, dan sebagainya. Di Indonesia, SPBU dijaga oleh para petugas yang melayani para pelanggan dalam pembelian bahan bakar. ${ }^{1}$

Salah satu keluhan para konsumen yang sering terjadi adalah adanya kecurangan dalam pengisian bahan bakar di SPBU.Konsumen berhak mendapatkan jumlah bahan bakar sesuai dengan yang mereka bayar. Antara hak dan kewajiban haruslah berjalan secara parallel dan proposional. Pelanggan membayar sesuai dengan harga dan sekaligus pelanggan juga mendapatkan bahan bakar dengan jumlah yang sesuai. Bahkan, apabila terjadi masalah sekecil apapun, petugas SPBU haruslah menjadi penyalur keluhan masyarakat.

Di Bali sendiri, kondisi terjadinya kecurangan pada SPBU juga cukup sering ditemui. Salah satu kasus yang sempat tersebar di media, yaitu di Kabupaten Buleleng. Kejadian tersebut bermula ketika salah satu konsumen hendak melihat meteran pada SPBU, namun salah satu petugas di SPBU tersebut menutupi meterannya. Ketika selesai mengisi BBM, kemudian konsumen tersebut melihat meteran secara langsung, namun petugas tersebut langsung me-reset meterannya dimulai dari angka nol kembali. Ulah oknum petugas SPBU yang diduga curang itupun diunggah ke media sosial, hingga berbagai komentar negatif muncul. Sebagai petugas SPBU yang baik, seharusnya sebelum menjual BBM kepada Konsumen, pegawai SPBU wajib untuk

${ }^{1}$ Angga Kurniawan A.P, Rika Lestari, Riska Fitriani, 2016, "Perlindungan Keselamatan Dan Kesehatan Kerja Pada Pekerja Stasiun Pengisian Bahan Bakar Umum (SPBU) Di Kota Pekanbaru”, JOM Fakultas Hukum Universitas Riau Vol. 3 No. 1 edisi 2016, URL: https://media.neliti.com/media/publications/115043ID-perlindungan-keselamatan-dan-kesehatan-k.pdf, diakses tanggal 05 Februari 2019 Pukul 15.00 Wita 
memberitahukan kepada konsumen bahwa takaran dimulai dari angka nol. Dilihat dari kasus tersebut yang terjadi di Buleleng, tidak menutup kemungkinan jika hal serupa juga dapat terjadi pada beberapa daerah lainnya yang ada di Bali.

Berdasarkan latar belakang masalah diatas, maka diangkatlah permasalahan tersebut dalam bentuk karya tulis dengan judul "Perlindungan Konsumen Terhadap Kecurangan Pengisian Bahan Bakar Minyak Pada Stasiun Pengisian Bahan Bakar Umum Di Bali".

\subsection{Rumusan Masalah}

1. Bagaimana tanggungjawab pihak SPBU terhadap kecurangan dalam pengisian BBM kepada konsumen di Bali?

2. Bagaimana perlindungan hukum bagi konsumen terhadap kecurangan pengisian BBM di SPBU di Bali?

\subsection{Tujuan Penulisan}

Tujuan dari penulisan jurnal ini adalah:

1. Untuk mengetahui tanggung jawab pihak SPBU terhadap kecurangan dalam pengisian BBM kepada konsumen di Bali.

2. Untuk mengetahui perlindungan hukum bagi konsumen terhadap kecurangan pengisian BBM di SPBU di Bali. 


\section{ISI MAKALAH}

\subsection{Metode Penelitian}

Metodologi penelitian dalam penulisan penelitian ini adalah menggunakan jenis penelitian yang bersifat atau bermetode Yuridis-Empiris yaitu mengkaji permasalahan berdasarkan aturan-aturan hukum yang ada, kemudian mengkaitkannya dengan fakta-fakta yang bermunculan di masyarakat. ${ }^{2}$

\subsection{Hasil dan Pembahasan}

\subsubsection{Tanggungjawab Pihak SPBU Terhadap Kecurangan Dalam Pengisian BBM Kepada Konsumen Di Bali}

Dalam kamus hukum, tanggung jawab adalah suatu keseharusan bagi seseorang untuk melaksanakan apa yang telah diwajibkan kepadanya. ${ }^{3}$ Secara umum, tujuan umum terhadap pertanggungjawaban pelaku usaha ada 3 (tiga) tujuan utama, yakni pemberian kompensasi (ganti kerugian), penyebaran resiko, dan pencegahan. ${ }^{4}$ UUPK mencoba untuk mencegah terjadi eksploitasi yang terindikasi merugikan konsumen melalui larangan terhadap perbuatan-perbuatan tertentu dan tanggang jawab pelaku usaha terhadap konsumen. Selain perbuatan yang dilarang oleh pelaku usaha, perlindungan konsumen juga mengenal konsep pertanggung jawaban pelaku usaha. ${ }^{5}$

2Soerjono Soekanto, 2014, Pengantar Penelitian Hukum, UI Press, Jakarta, hal. 13.

${ }^{3}$ Andi Hammzah, 2005, Hukum Acara Pidana Indonesia, Edisi Revisi, Sapta Artha Jaya hal. 26

${ }^{4}$ Celina Tri Siwi Kristiyanti, 2009, Hukum Perlindungan Konsumen, Sinar Grafika, Jakarta, hal. 22.

${ }^{5}$ Abdul Halim Barkatulah, 2008, Hukum Perlindungan Konsumen (Kajian Teoretis dan Perkembangan Pemikiran, Nusa Media, Bandung, hal 7. 
Dalam UUPK, tanggung jawab pelaku usaha tercantum pada Pasal 19 yang mengatur mengenai pemberian ganti rugi oleh pelaku usaha terhadap konsumen.Tanggung jawab pelaku usaha atas produk yang merugikan konsumen mempunyai beberapa prinsip-prinsip hukum yang dibedakan sebagai berikut:

1. Prinsip Tanggung Jawab Berdasarkan Unsur Kesalahan ${ }^{6}$

2. Prinsip Praduga Untuk Selalu Bertanggung Jawab

3. Prinsip Praduga Untuk Tidak Selalu Bertanggung Jawab

4. Prinsip Tanggung Jawab Mutlak

5. Tanggung Jawab Dengan Pembatasan

Dari sudut pandang Hukum Perlindungan Konsumen, prinsip yang digunakan dalam tanggung jawab, di antaranya adalah sebagai berikut :

1. Prinsip Tanggung Jawab Berdasarkan Kelalaian atau Kealpaan ${ }^{7}$

2. Prinsip Tanggung Jawab Berdasarkan Wanprestasi

3. Prinsip Tanggung Jawab Mutlak

Terkait dengan pembahasan sebelumnya, apabila terjadi suatu kecurangan dalam pengisian BBM terhadap konsumen, pihak SPBU wajib memberikan ganti rugi berupa uang atau sejumlah bahan bakar yang dirasa telah dikurangi tersebut. Namun untuk mengklaim kerugian tersebut, konsumen harus dapat membuktikan kecurangan yang terjadi. Untuk

\footnotetext{
${ }^{6}$ Shidarta, 2000, Hukum Perlindungan Konsumen Indonesia, PT Grasindo, Jakarta, hal. 59.

7Zulham, 2013, Hukum Perlindungan Konsumen, Kencana, Jakarta, hal.83
} 
membuktikan kecurangan tersebut, beberapa cara dapat dilakukan pungkasnya, seperti

1. Permainan flow meter / nozzle mesin. Seandainya konsumen merasa bahwa salah satu petugas operator SPBU melakukan permainan pada flow meter pengisi BBM, bentuk tanggung jawab yang diberikan oleh pihak SPBU yaitu memberikan struk pembelian BBM untuk membuktikan apakah benar telah terjadi kecurangan terhadap pengisian bahan bakar tersebut. Apabila memang terbukti, maka SPBU akan memberikan ganti rugi berupa uang atupun bahan bakar sejumlah kerugian yang diderita oleh konsumen tersebut.

2. Jumlah kembalian yang tidak sesuai. Apabila konsumen mengalami hal ini, bentuk tanggung jawab yang dilakukan yaitu dengan mengecek struk pembelian bahan bakar oleh konsumen, apabila memang terbukti operator tidak mengembalikan uang konsumen sesuai dengan jumlah pembelian, maka pihak SPBU akan memberikan jumlah uang tersebut atau memberikan ganti rugi berupa BBM sesuai dengan kekurangan jumlah kembalian uangnya.

Namun demikian, apabila ada suatu kecurangan yang dirasakan, konsumen juga tidak boleh langsung berpikir bahwa kesalahan terjadi diakibatkan oleh oknum sumber daya manusianya. Karena ada 2 kemungkinan yang dapat terjadi, yaitu pertama kesalahan dapat terjadi disebabkan oleh aspek manusia nya, dan yang kedua juga dapat terjadi oleh aspek mesin. Sama dengan penjelasan sebelumnya, manakala mesin dalam keadaan buruk, sebaik atau sejujur apapun pihak manusia sebagai operator SPBU bekerja, maka ketidakmaksimalan dalam pengisian 
BBM pun dapat terjadi. Namun apabila memang benar-benar terbukti bahwa ada oknum nakal yang bermain curang, maka oknum pekerja tersebut akan ditindak sesuai dengan peraturan perundang-undangan yang berlaku baginya.

\subsubsection{Perlindungan Hukum Bagi Konsumen Terhadap Kecurangan Pengisian BBM Pada SPBU Di Bali}

Pelaku usaha dalam menawarkan barang dan atau jasa dilarang melakukan dengan cara pemaksaan atau cara lain yang dapat menimbulkan gangguan baik fisik maupun psikis terhadap konsumen, hal ini sebagaimana diatur dalam pasal 15 UU Perlindungan Konsumen. Atas dasar kondisi sebagaimana dipaparkan diatas, perlu upaya pemberdayaan konsumen yang dapat melindungi kepentingan konsumen secara intergratif dan komprehensif serta dapat diterapkan secara efektif di masyarakat. ${ }^{8}$

Perlindungan hukum bagi konsumen diperuntukkan bagi konsumen untuk menjaga hak-haknya. Dalam penjelasan UUPK dikatakan konsumen berada dalam posisi yang lemah. Karena itu ia harus dilindungi oleh hukum. Salah satu tujuan hukum adalah memberikan perlindungan kepada masyarakat. 9

8 A.A. Gde Agung Brahmanta, Ibrahim. R, I Made Sarjana, 2016, "Perlindungan Hukum Bagi Konsumen Dalam Perjanjian Baku Jual Beli Perumahan Dengan Pihak Pengembang Di Bali”, Acta Comitas, Vol. 1 No. 2 edisi Oktober 2016, hal. 217, URL: https://ojs.unud.ac.id/index.php/ActaComitas/article/view/24953/16186, diakses tanggal 10 Februari 2019 Pukul 13.00 Wita

9 Ni Putu Januaryanti Pande, 2017, "Perlindungan Konsumen Terhadap Produk Kosmetik Impor Yang Tidak Terdaftar Di BBPOM Denpasar”, Jurnal Magister Hukum Udayana (Udayana Master Law Jurnal) Vol. 6 No.1 edisi Mei 2017, hal. 18 , URL https://ojs.unud.ac.id/index.php/jmhu/article/view/22288/20922, diakses tanggal 10 Februari 2019 Pukul 13.00 Wita 
Philipus M. Hadjon, berpendapat bahwa sarana perlindungan Hukum ada dua macam yaitu Sarana Perlindungan Hukum Preventif dan Sarana Perlindungan Hukum Represif.

\section{Perlindungan Hukum Preventif}

Perlindungan yang diberikan oleh pemerintah dengan tujuan untuk mencegah sebelum terjadinya pelanggaran. Hal ini terdapat dalam peraturan perundang-undangan dengan maksud untuk mencegah suatu pelanggaran serta memberikan rambu-rambu atau batasan-batasan dalam melakukan sutu kewajiban.

\section{Perlindungan Hukum Represif}

Perlindungan hukum represif merupakan perlindungan akhir berupa sanksi seperti denda, penjara, dan hukuman tambahan yang diberikan apabila sudah terjadi sengketa atau telah dilakukan suatu pelanggaran.

Dalam melindungi konsumen BBM di Bali, upaya perlindungan hukum yang dilakukan dalam bentuk preventif yaitu dengan dilakukannya kegiatan tera ulang terhadap mesin atau nozzle SPBU demi menjaga keakuratan takaran bahan bakar yang diterima konsumen, agar hak konsumen dapat terpenuhi sebagaimana mestinya. Dari hasil wawancara kepada Bapak I Wayan Gede Sudartha selaku Penera Penyelia UPT Metrologi Legal Disperindag Kota Denpasar mengatakan, sebagai upaya pelaksanaan perlindungan kepentingan konsumen, perlu adanya jaminan dalam kebenaran pengukuran serta adanya ketertiban dan kepastian hukum dalam pemakaian satuan ukur, standar satuan, metode pengukuran dan UTTP. Adanya standarisasi ini penting untuk memastikan akurasi dari obyek yang diukurnya yang dapat memberikan jaminan ketepatan pengukuran serta 
pengendalian mutu khususnya dalam hal ini terkait takaran BBM. Salah satu upaya yang dilakukan Disperindag Bali dalam pelaksanaan perlindungan konsumen BBM, dengan melakukan tera ulang melalui UPT Metrologi Legal. Tera ulang merupakan pengujian kembali terhadap timbangan, takaran dan ukuran yang digunakan dalam perdagangan. Dilaksanakannya tera ulang pada SPBU ini, bertujuan untuk menghindari konsumen dari indikasiindikasi kecurangan takaran dan menghindari konsumen dari kerugian akibat pembelian BBM yang tidak sesuai dengan ukurannya

Selain itu, upaya perlindungan hukum yang dilakukan dalam bentuk represif, dalam pelaksanan perlindungan hukum terhadap konsumen, Disperindag bekerja sama dengan aparat hukum terkait yaitu kepolisian melakukan tindakan berupa penyegelan terhadap SPBU yang terbukti melanggar. Dengan dilakukan nya penyegelan terhadap SPBU-SPBU curang di Bali, maka diharapkan akan memberi efek jera terhadap pelaku usaha agar tidak melakukan kecurangan. Dalam penindakan penyegelan terhadap SPBU-SPBU nakal tersebut, Disperindag diposisikan sebagai Saksi Ahli.

Selain daripada upaya yang dilakukan Pemerintah dalam melindungi konsumen BBM agar terhindar dari segala tindakan yang merugikan, sebagai konsumen juga seharusnya lebih cerdas dan kritis apabila menemui masalah-masalah yang berhubungan dalam pengisian BBM di SPBU. Walaupun dari pihak perusahaan sering mengklaim tidak bahwa tidak terjadi kecurangan saat pengisian bahan bakar di SPBU. Namun, pada kenyataannya ada saja masyarakat yang merasa dicurangi saat mengisi bahan bakar di SPBU. Lepas dari semua itu, sebagai masyarakat yang peduli 
pada diri sendiri dan juga orang lain, berikut agar tidak dicurangi saat melakukan pengisian bahan bakar di SPBU.

\section{a. Cek meteran awal}

Meterannya harus angka nol. Dulu di tahun 1990an, sebelum ada pembenahan besar-besaran hingga terlahir slogan "pasti pas," petugas SPBU sering mengisi tangki pelanggan dengan meteran yang tidak dimulai dari nol. Meski trik curang itu jarang dilakukan, tidak ada salahnya jika tetap memeriksa angka meteran di pom.

b. Cek meteran akhir

Jangan lupa juga cek metaran pom setelah mengisi bensin, terutama saat mengisi dengan request "full tank." Kalo Petugas bisa aja bertindak curang dengan me-mark up meteran. Harga yang seharusnya bisa saja dibulatkan naik.

c. Waspadai pengisian manual

Seharusnya, nozzle jaman sekarang bisa dioperasikan otomatis. Ketika bensin sudah penuh, nozzle akan secara otomatis berhenti mengeluarkan bensin. Waspadai petugas-petugas yang masih memakai nozzle manual karena bisa saja petugas tersebut memberhentikan pengisian bensin sebelum waktunya.

d. Minta struk

Biasakan meminta bukti pembayaran walaupun tidak ditawari oleh operator. Karena, semua keterangan jumlah pengisian bensin, harga asli, uang yang dibayarkan, bahkan kembalian yang harus dikeluarin SPBU akan tertera di situ. ${ }^{10}$

10 Tampang.com, 2018, 6 Tips Agar Terhindar Dari Kecurangan Saat IsiBahan Bakar Di SPBU, URL : https://tampang.com/detail/6-tips-agarterhindar-dari-kecurangan-saat-isi-bahan-bakar-di-spbu-7190.php, tanggal akses 01 Agustus 2018. 


\section{PENUTUP}

\subsection{Kesimpulan}

Berdasarkan pemaparan terhadap permasalahan di atas maka dalam hal ini dapat disimpulkan yaitu:

1. Bentuk tanggung jawab yang dapat dilakukan oleh pihak SPBU terhadap kecurangan yang terjadi pada pengisian BBM yaitu dengan memberikan ganti rugi berupa uang tunai ataupun penggantian dalam bentuk BBM sesuai dengan jumlah yang diakibatkan dalam kecurangan tersebut.

2. Upaya yang dilakukan dalam pelaksanaan perlindungan hukum bagi konsumen BBM di Bali yaitu dengan dilaksanakannya kegiatan uji tera dan tera ulang terhadap mesin pompa pada setiap SPBU. Selain itu, dalam pelaksanaan hukumnya, apabila SPBU terbukti melakukan kecurangan, maka Disperindag bekerjasama dengan aparat hukum lainnya melakukan tindakan penyegelan terhadap SPBU tersebut untuk memberikan efek jera kepada para pelaku usaha.

\subsection{Saran}

Berdasarkan pemaparan terhadap kesimpulan diatas maka dalam hal ini dapat diberikan saran, yaitu:

1. Perlu diadakannya perbaikan Regulasi, berupa memasukkan aturan pelaksana ganti kerugian kepada konsumen yang telah dirugikan. Perlu ada kajian lanjutan dalam menyusun langkah yang tepat dan dapat diimplementasikan, mengingat metode pengganti kerugian yang ada sangatlah 
belum mendukung dalam pemenuhan hak ganti rugi konsumen.

2. Kedepannya perlu diterapkan sistem pembayaran secara elektronik atau yang biasa disebut e-money dalam transaksi pembeli BBM, agar konsumen terhindar dari kecurangan oknum-oknum operator SPBU yang tidak jujur dalam jumlah pengembalian uang, dimana sistem e-money ini juga akan lebih praktis dalam penggunaannya.

\section{DAFTAR PUSTAKA}

\section{BUKU}

Halim Barkatulah, Abdul, 2008, Hukum Perlindungan Konsumen (Kajian Teoretis dan Perkembangan Pemikiran, Nusa Media, Bandung.

Hammzah Andi, 2005, Hukum Acara Pidana Indonesia, Edisi Revisi, Sinar Grafika, Jakarta.

Shidarta, 2000, Hukum Perlindungan Konsumen Indonesia, PT Grasindo, Jakarta.

Soekanto, Soerjono, 2014, Pengantar Penelitian Hukum, UI Press, Jakarta.

Tri Siwi Kristiyanti, Celina, 2009, Hukum Perlindungan Konsumen, Sinar Grafika, Jakarta.

Zulham, 2013, Hukum Perlindungan Konsumen, Kencana, Jakarta.

\section{JURNAL}

Angga Kurniawan A.P, Rika Lestari, Riska Fitriani, 2016, "Perlindungan Keselamatan Dan Kesehatan Kerja Pada Pekerja Stasiun Pengisian Bahan Bakar Umum (SPBU) Di Kota Pekanbaru", JOM Fakultas Hukum Universitas Riau Vol. 3 No. 3 , URL https://media.neliti.com/media/publications/115043-IDperlindungan-keselamatan-dan-kesehatan-k.pdf

A.A. Gde Agung Brahmanta, Ibrahim. R, I Made Sarjana, 2016, "Perlindungan Hukum Bagi Konsumen Dalam Perjanjian Baku Jual Beli Perumahan Dengan Pihak Pengembang Di Bali", Acta Comitas, Vol. 1 No. 2 Oktober 2016, hal. 217, URL: 
https://ojs.unud.ac.id/index.php/ActaComitas/article/view $\not 24953 / 16186$

Ni Putu Januaryanti Pande, "Perlindungan Konsumen Terhadap Produk Kosmetik Impor Yang Tidak Terdaftar Di BBPOM Denpasar", Jurnal Magister Hukum Udayana (Udayana Master Law Jurnal) Vol. 6 No.1 edisi Mei 2017, hal. 18, URL : https://ojs.unud.ac.id/index.php/imhu/article/view/22288 $\underline{20922}$

\section{INTERNET}

Tampang.com, 2018, 6 Tips Agar Terhindar Dari Kecurangan Saat Isi Bahan Bakar Di SPBU, URL : https://tampang.com/detail/6-tips-agar-terhindar-darikecurangan-saat-isi-bahan-bakar-di-spbu-7190.php, tanggal akses 01 Agustus 2018.

\section{PERATURAN PERUNDANG-UNDANGAN}

Kitab Undang-Undang Hukum Perdata, 2009, Burgerlijk Wetboek voor Indonesie, diterjemahkan oleh R. Subekti \& R. Tjitrosudibio, Balai Pustaka, Jakarta.

Kitab Undang-Undang Hukum Pidana, 2006, diterjemahkan oleh Moeljatno, Bumi Aksara, Jakarta.

Indonesia, Undang-undang Nomor 2 Tahun 1981 Tentang Metrologi Legal. Lembaran Negara Republik Indonesia Tahun 1981 Nomor 1,. Tambahan Lembaran Negara Nomor 3193

Indonesia, Undang-undang Nomor 8 Tahun 1999 Tentang Perlindungan Konsumen. Lembaran Negara Republik Indonesia Tahun 1999 Nomor 42, Tambahan Lembaran Negara Nomor 3821

Indonesia, Undang-undang Nomor 22 Tahun 2001 Tentang Minyak dan Gas Bumi. Lembaran Negara Republik Indonesia Tahun 2001 Nomor 136, Tambahan Lembaran Negara Nomor 4152 